\title{
OPTIMISING FLOW STRESS INPUT FOR MACHINING SIMULATIONS USING TAGUCHI METHODOLOGY
}

\author{
Vijay Sekar, K. S. ${ }^{*} \&$ Pradeep Kumar, M.* \\ * Department of Mechanical Engineering, SSN College of Engineering, Chennai, India \\ ${ }^{* *}$ Department of Mechanical Engineering, CEG, Anna University, Chennai, India \\ E-Mail: vijaysekarks@ssn.edu.in, pradeep@annauniv.edu
}

\begin{abstract}
Flow stress is a vital input data for successful simulation of a machining process. However the flow stress data obtained from experiments do not represent the practical machining conditions which induce errors in the simulated output. In this research work the flow stress of Ti6Al4V titanium alloy is improved through a new integrated Taguchi - Finite element optimisation technique. The finite element (FE) outputs for cutting force, feed force and chip thickness ratio are compared with the results from the orthogonal machining process and an optimum set of material parameters of the Johnson - Cook (JC) flow stress equation is identified. The optimised flow stress is found to improve the simulated cutting forces by $3-16 \%$, feed forces by $2-25 \%$, chip thickness ratio by $0-19 \%$ over flow stress computed from conventional JC model parameters. The yield strength parameter of the JC model impacts the simulation results the most and the JC material constitutive law is found to be robust in flow stress characterisation with the optimized parameters.

(Received in March 2011, accepted in September 2011. This paper was with the authors 1 month for 1 revision.)
\end{abstract}

Key Words: Taguchi Optimisation, Finite Element Simulation, Orthogonal Cutting, Titanium Alloys, Flow Stress Models

\section{INTRODUCTION}

Modelling and simulations of the machining process depends on the accuracy of the input data such as flow stress, friction between chip - tool and thermo physical properties of work and tool materials. Flow stress is a fundamental and critical input parameter for successfully modelling the physical behaviour of materials in a machining process. The flow stress is generally measured from Split Hopkinson Pressure Bar (SHPB) tests which use a limited range of strains and strain rates unlike machining which encounters very high strains and strain rates and this limits their direct application to numerical simulations of the machining process $[1,2]$. The flow stress obtained from SHPB tests is mathematical fit into semi empirical flow stress models such as the JC model and its material parameters computed from least square techniques. It has been reported that flow stress computed from such constitutive material models vary with its material parameters which induce approximation errors in machining simulations $[3,4]$. To overcome this, it has been suggested that SHPB data should be used as a starting point while the flow stress model parameters need to be computed from a combination of analytical chip formation models and machining tests [5]. A number of flow stress models have been compared for their accuracy in modelling the machining process with varied results $[6,7]$. Many researchers have developed their own flow stress models citing limitations in existing ones especially for simulating titanium alloy machining [8-11].

The literature so far indicates the inaccuracies involved in using SHPB data in machining simulations and also the approximations induced by the mathematical techniques used to compute the flow stress model parameters. Since various flow stress models further induce their own inaccuracies, this work explores the possibility of optimising an existing set of flow 
stress parameters of the popular JC model to suit titanium alloy machining. The literature in optimisation of flow stress and its parameters shows the application of genetic algorithms [12], evolutionary computational algorithms [13] and artificial neural networks [14] with reasonable success. However the process is cumbersome requiring complex mathematical computations as in the evolutionary computational process and large amount of input material data for the neural network model.

In this research work the simple yet robust Taguchi design of experiments concept has been adopted to find an optimised set of material parameters of the JC model for titanium alloy machining simulation from four material sets reported in literature [13, 15-21]. The integrated Taguchi - Finite element approach has not been used before in flow stress optimisation. The cutting force, feed force and chip thickness ratio from orthogonal cutting tests with a tube of titanium alloy on a Lathe machine is compared with the FE results. The effective stress, strain, strain rate and temperature are analysed and a detailed sensitivity analysis of the JC material model parameters are performed.

\section{JOHNSON AND COOK MATERIAL MODEL}

Johnson and Cook [22] developed a phenomenological model based on visco plastic nature:

$$
\sigma=\left[\mathrm{A}+\mathrm{B} \varepsilon^{\mathrm{n}}\right]\left[1+\mathrm{C} \ln \left(\varepsilon^{\prime} / \varepsilon_{o}^{\prime}\right)\right]\left[1-\left\{\left(T-T_{\text {room }}\right) /\left(T_{\text {melt }}-T_{\text {room }}\right)\right\}^{\mathrm{m}}\right]
$$

where $\sigma$ is the equivalent flow stress, $\varepsilon$ the equivalent plastic strain, $\varepsilon^{\prime}$ the strain rate, $\varepsilon_{o}^{\prime}$ the reference plastic strain rate, $T$ the temperature of the work material at which the experiments are performed, $T_{\text {melt }}$ the melting temperature of the work material and $T_{\text {room }}$ the room temperature. The parameter $A$ represents the initial yield strength of the work material, $B$ the hardening modulus, $C$ the strain rate sensitivity coefficient, $n$ the hardening coefficient and $m$ the thermal softening coefficient. The strain rate is normalised with the reference plastic strain rate usually assumed as $1 \mathrm{~s}^{-1}$. Table I shows the JC parameters of Ti6Al4V alloy.

Table I: JC model material parameters for Ti6A14V.

\begin{tabular}{|c|c|c|c|c|c|}
\hline \multirow{2}{*}{ JC Models } & \multicolumn{5}{|c|}{ JC Parameters } \\
\cline { 2 - 6 } & $\boldsymbol{A}(\mathrm{MPa})$ & $\boldsymbol{B}(\mathrm{MPa})$ & $\boldsymbol{C}$ & $\boldsymbol{n}$ & $\boldsymbol{m}$ \\
\hline M1 [15] & 782.7 & 498.4 & 0.028 & 0.28 & 1 \\
\hline M2 [13] & 987.8 & 761.5 & 0.01516 & 0.41433 & 1.516 \\
\hline M3 [16] & 1104 & 1036 & 0.01390 & 0.6349 & 0.7794 \\
\hline M4 [17] & 1098 & 1092 & 0.014 & 0.93 & 1.1 \\
\hline
\end{tabular}

M1 parameter set were identified from SHPB tests at high strain rate mechanical testing conditions at a temperature range of $700^{\circ} \mathrm{C}-1100^{\circ} \mathrm{C}$, strain rate of $2000 \mathrm{~s}^{-1}$, plastic strain up to 0.3 and reference strain rate of $10^{-5} \mathrm{~s}^{-1}$ [15]. M2 set based on SHPB data at room temperature, strain rate up to $2150 \mathrm{~s}^{-1}$, plastic strain up to 0.57 and reference strain rate of $1 \mathrm{~s}^{-1}$ was identified from cooperative particle swarm optimization (CPSO) process [13]. M3 is an optimized form of the JC model computed from SHPB at a temperature up to $755 \mathrm{~K}$, strain rate up to $1 \mathrm{~s}^{-1}$, plastic strain up to 0.3 and reference strain rate of $1 \mathrm{~s}^{-1}$ [16]. M4 is identified from least square fit to power law equation at a temperature up to $1200^{\circ} \mathrm{C}$, strain rate up to $10^{4} \mathrm{~s}^{-1}$, strain up to 0.3 and reference strain rate of $1 \mathrm{~s}^{-1}[17]$.

\section{TAGUCHI DESIGN OF EXPERIMENTS}

Taguchi developed a scientific design optimisation technique to reduce the number of experiments required to optimise the process parameters in a manufacturing process [23]. This 
concept has been used to optimise the JC parameters and the flow stress for Ti6Al4V titanium alloys. The five parameters of the JC model: $A, B, C, n$ and $m$ each represents a unique material property which define the deformation behaviour of materials in the plastic state. Table I shows the four unique sets of the five parameters of the JC model. Taguchi classifies the problem as a 5 parameter 4 level one. A full factorial design optimisation approach would result in $5^{4}=625$ sets of parameters. It is not feasible to compute the flow stress data for this many sets. Taguchi suggests the fractional factorial approach to minimise the number of simulations without affecting the quality of the design process. The four JC material model sets are input to Minitab software to create a Taguchi design matrix based on the $\mathrm{L}_{16}$ orthogonal arrays. Table II shows the Taguchi design matrix created in Minitab software. The flow stress for a range of strain $(0.1-1)$, strain rates $\left(1-10^{5} \mathrm{~s}^{-1}\right)$, temperatures $(298-1573 \mathrm{~K})$ and a reference strain rate of $1 \mathrm{~s}^{-1}$ is computed for the parameter sets defined in Table I and Table II and input to the FE preprocessor in Deform 2D software. The Taguchi - FE results are input into Minitab software and a sensitivity analysis was conducted to test the impact of the five parameters on the FE responses across cutting speeds.

Table II: Taguchi design matrix based on $\mathrm{L}_{16}$ orthogonal array.

\begin{tabular}{|c|c|c|c|c|c|}
\hline \multirow{2}{*}{ Trials } & \multicolumn{5}{|c|}{ JC Parameters } \\
\cline { 2 - 6 } & $\boldsymbol{A}(\mathrm{MPa})$ & $\boldsymbol{B}(\mathrm{MPa})$ & $\boldsymbol{C}$ & $\boldsymbol{n}$ & $\boldsymbol{m}$ \\
\hline $\mathbf{1}$ & 782.7 & 498.4 & 0.028 & 0.28 & 1 \\
\hline $\mathbf{2}$ & 782.7 & 761.5 & 0.01516 & 0.41433 & 1.516 \\
\hline $\mathbf{3}$ & 782.7 & 1036 & 0.0139 & 0.6349 & 0.7794 \\
\hline $\mathbf{4}$ & 782.7 & 1092 & 0.014 & 0.93 & 1.1 \\
\hline $\mathbf{5}$ & 987.8 & 498.4 & 0.01516 & 0.6349 & 1.1 \\
\hline $\mathbf{6}$ & 987.8 & 761.5 & 0.028 & 0.93 & 0.7794 \\
\hline $\mathbf{7}$ & 987.8 & 1036 & 0.014 & 0.28 & 1.516 \\
\hline $\mathbf{8}$ & 987.8 & 1092 & 0.0139 & 0.41433 & 1 \\
\hline $\mathbf{9}$ & 1104 & 498.4 & 0.0139 & 0.93 & 1.516 \\
\hline $\mathbf{1 0}$ & 1104 & 761.5 & 0.014 & 0.6349 & 1 \\
\hline $\mathbf{1 1}$ & 1104 & 1036 & 0.028 & 0.41433 & 1.1 \\
\hline $\mathbf{1 2}$ & 1104 & 1092 & 0.01516 & 0.28 & 0.7794 \\
\hline $\mathbf{1 3}$ & 1098 & 498.4 & 0.014 & 0.41433 & 0.7794 \\
\hline $\mathbf{1 4}$ & 1098 & 761.5 & 0.0139 & 0.28 & 1.1 \\
\hline $\mathbf{1 5}$ & 1098 & 1036 & 0.01516 & 0.93 & 1 \\
\hline $\mathbf{1 6}$ & 1098 & 1092 & 0.028 & 0.6349 & 1.516 \\
\hline
\end{tabular}

\section{ORTHOGONAL CUTTING EXPERIMENTS}

Orthogonal cutting experiments were conducted on a Lathe machine tool with a tube of Ti6A14V titanium alloy as work piece and a tungsten carbide - cobalt insert coated with a pressure vapor deposit of titanium aluminum nitride as cutting tool under dry conditions.

Table III: Experimental details for machining titanium alloy.

\begin{tabular}{|l|l|}
\hline Work material & Ti6Al4V alloy $($ Tube $)$ \\
\hline Work dimensions $(\mathrm{mm} \times \mathrm{mm})$ & $320 \times 59.3($ length $\times$ outer diameter $)$ \\
\hline Tube thickness $(\mathrm{mm})$ & 2 \\
\hline Tool material & TiAlN coated tungsten carbide insert \\
\hline Tool rake angle $/$ clearance angle & $-5^{\circ} / 5^{\circ}$ \\
\hline Insert & $\mathrm{CNMG} 120408 \mathrm{MP}, \mathrm{KC} 5010$ \\
\hline Cutting speeds $(\mathrm{m} / \mathrm{min})$ & $25,40,61$ and 93 \\
\hline Feed rate $(\mathrm{mm} / \mathrm{rev})$ & 0.191 \\
\hline
\end{tabular}


A Kistler dynamometer (9257 B) coupled with a multi channel charge amplifier and data acquisition software was calibrated and then used to record the cutting and feed forces. The segmented chip from each cutting cycle was observed under a scanning electron microscope (SEM) and the mean chip thickness measured. The chip thickness ratio (CTR) was calculated as the ratio of uncut chip thickness and mean chip thickness. Table III shows the experimental details for machining used in this work.

\section{FINITE ELEMENT MODELLING AND SIMULATION}

A 2D orthogonal cutting FE model based on plain strain assumption and the Lagrange formulation was developed in Deform 2DC software. The experimental conditions were replicated in the model. The work piece was modelled as a viscoplastic model and meshed with 5900 iso parametric quadrilateral elements. The tool was modelled as a rigid material and meshed with 250 elements. Fig. 1a shows the FE model with the boundary conditions. The work piece was fully constrained in $\mathrm{X}$ and $\mathrm{Y}$ directions along the left and bottom sides. Fig. $1 \mathrm{~b}$ shows the work and tool geometries with the mesh. The thermo physical properties of the work and tool materials and the flow stress (for each simulation run) computed from the four basic models (Table I) and Taguchi design matrix (Table II) were input to the FE code.
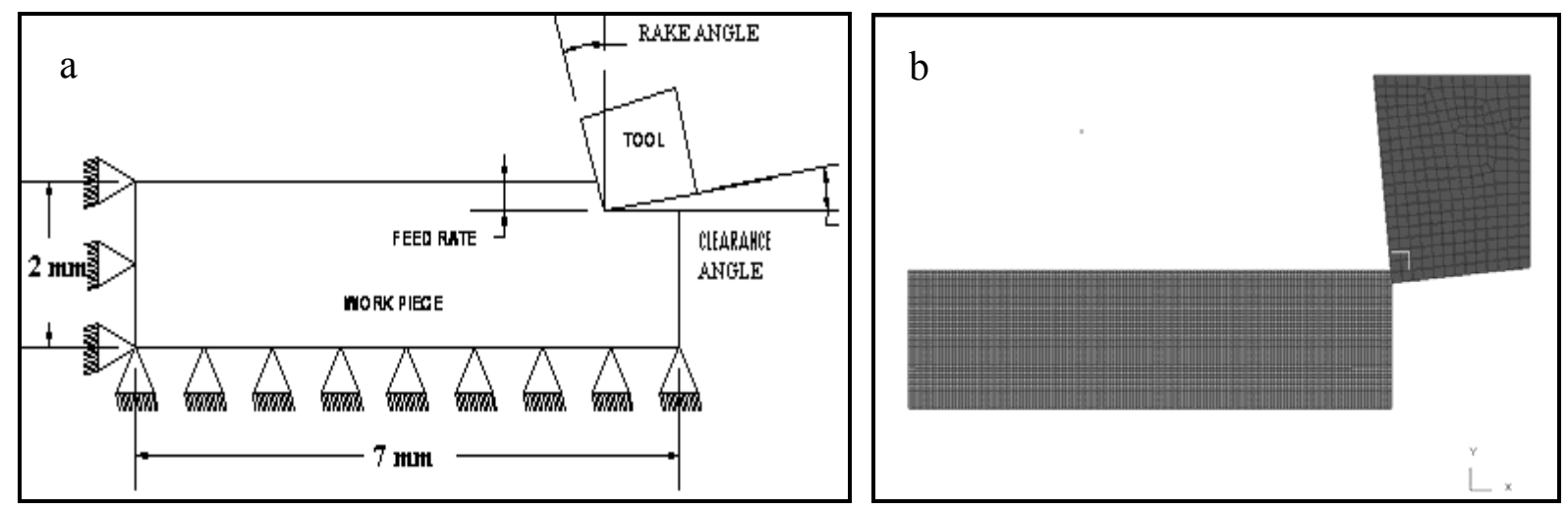

Figure 1: a) FE Boundary conditions, b) Mesh of work and tool.

\section{RESULTS AND DISCUSSION}

\subsection{Cutting force predictions}

Table IV shows the mean cutting force predictions (error in brackets indicating the percentage error with respect to experiments) by the four JC models in correlation with the experiments. Model M2 predicts the mean cutting force with good correlation to experiments for cutting speeds of 25, 61 and $93 \mathrm{~m} / \mathrm{min}$ and Model M1 predicts the cutting force at $40 \mathrm{~m} / \mathrm{min}$ with good correlation to experiments. The good predictions of M2 model especially at $25 \mathrm{~m} / \mathrm{min}$ (less than $10 \%$ error) and $93 \mathrm{~m} / \mathrm{min}$ (less than $6 \%$ error) can be attributed to the optimised JC parameters computed by the cooperative particle swarm optimisation (CPSO) method based on evolutionary computational algorithms [13] and the M1 predictions (less than $17 \%$ error) at $40 \mathrm{~m} / \mathrm{min}$ can be attributed to the computation of flow stress at conditions of high strain rate and temperatures [15]. M4 model predictions were marginally better due to the higher strain rates $\left(10^{4} \mathrm{~s}^{-1}\right)$ used in the flow stress experiments [17] while M3 model gave relatively poor predictions due to the low values of strains and strain rates employed in the quasi static computation of flow stress [16]. 
Table IV: Cutting force predictions by the JC models.

\begin{tabular}{|c|c|c|c|c|}
\hline \multirow{2}{*}{ JC models } & \multicolumn{4}{|c|}{ Cutting force $(\mathrm{N})$} \\
\cline { 2 - 5 } & $25 \mathrm{~m} / \mathrm{min}$ & $40 \mathrm{~m} / \mathrm{min}$ & $61 \mathrm{~m} / \mathrm{min}$ & $93 \mathrm{~m} / \mathrm{min}$ \\
\hline M1 & $659(-24.60)$ & $675(-16.35)$ & $639(-21.40)$ & $631(-14.96)$ \\
\hline M2 & $792(-9.38)$ & $670(-16.97)$ & $684(-15.86)$ & $702(-5.39)$ \\
\hline M3 & $636(-27.23)$ & $573(-28.99)$ & $563(-30.75)$ & $563(-24.12)$ \\
\hline M4 & $665(-23.91)$ & $628(-22.18)$ & $634(-22.01)$ & $634(-14.55)$ \\
\hline EXP & 874 & 807 & 813 & 742 \\
\hline
\end{tabular}

Table $\mathrm{V}$ shows the mean cutting force predictions of the Taguchi design matrix. The Trials 1, 5, 6, 8, 9, 10, 12, 13 and 14 simulated segmented chips typical of titanium alloys for all cutting speeds over the entire stroke length suggesting good flow stress characteristics. Trials 2, 3, 4, 7, 11, 15 failed to simulate chips for the entire stroke length though they were segmented indicating poor flow stress characteristics resulting in solution convergence errors.

Table V: Cutting force predictions by the design matrix.

\begin{tabular}{|c|c|c|c|c|}
\hline \multirow{2}{*}{ Trials } & \multicolumn{4}{|c|}{ Cutting force $(\mathrm{N})$} \\
\cline { 2 - 5 } & $25 \mathrm{~m} / \mathrm{min}$ & $40 \mathrm{~m} / \mathrm{min}$ & $61 \mathrm{~m} / \mathrm{min}$ & $93 \mathrm{~m} / \mathrm{min}$ \\
\hline $\mathbf{1}$ & $659(-24.60)$ & $675(-16.35)$ & $639(-21.40)$ & $631(-14.96)$ \\
\hline $\mathbf{2}$ & $653(-25.28)$ & $689(-14.62)$ & $642(-21.03)$ & $639(-13.88)$ \\
\hline $\mathbf{3}$ & $599(-31.46)$ & $652(-19.20)$ & $611(-24.84)$ & $604(-18.59)$ \\
\hline $\mathbf{4}$ & $632(-27.68)$ & $634(-21.43)$ & $637(-21.64)$ & $639(-13.88)$ \\
\hline $\mathbf{5}$ & $696(-20.36)$ & $647(-19.82)$ & $683(-15.99)$ & $668(-9.97)$ \\
\hline $\mathbf{6}$ & $771(-11.78)$ & $803(-0.49)$ & $727(-10.57)$ & $694(-6.46)$ \\
\hline $\mathbf{7}$ & $792(-9.38)$ & $790(-2.10)$ & $790(-2.82)$ & $790(+6.46)$ \\
\hline $\mathbf{8}$ & $804(-8.00)$ & $783(-2.97)$ & $741(-8.88)$ & $725(-2.29)$ \\
\hline $\mathbf{9}$ & $803(-8.12)$ & $764(-5.32)$ & $722(-11.19)$ & $662(-10.78)$ \\
\hline $\mathbf{1 0}$ & $818(-6.40)$ & $847(+4.95)$ & $746(-8.24)$ & $667(-10.10)$ \\
\hline $\mathbf{1 1}$ & $830(-5.03)$ & $883(+9.41)$ & $821(+0.98)$ & $824(+11.05)$ \\
\hline $\mathbf{1 2}$ & $691(-20.93)$ & $675(-16.35)$ & $664(-18.32)$ & $663(-10.64)$ \\
\hline $\mathbf{1 3}$ & $632(-27.68)$ & $561(-30.48)$ & $526(-35.30)$ & $517(-30.32)$ \\
\hline $\mathbf{1 4}$ & $727(-16.81)$ & $759(-5.94)$ & $660(-18.81)$ & $660(-11.05)$ \\
\hline $\mathbf{1 5}$ & $800(-8.46)$ & $762(-5.57)$ & $741(-8.85)$ & $762(+2.69)$ \\
\hline $\mathbf{1 6}$ & $891(+1.94)$ & $931(+15.36)$ & $903(+11.07)$ & $923(+24.39)$ \\
\hline
\end{tabular}

At $25 \mathrm{~m} / \mathrm{min}$, Trial 10 predicts the cutting force with $6.40 \%$ error better than model M2 by around $3 \%$. At $40 \mathrm{~m} / \mathrm{min}$ Trial 6 predicts with $0.49 \%$ error better than $\mathrm{M} 1$ by around $16 \%$. At $61 \mathrm{~m} / \mathrm{min}$ Trial 10 predicts with $8.24 \%$ error better than M2 by around $7.5 \%$. At 93 $\mathrm{m} / \mathrm{min}$ Trial 8 predicts with $2.29 \%$ error better than M2 by around $3 \%$. The improved cutting force predictions of Trials 6,8 and 10 of the Taguchi design matrix indicate improved flow stress characterisation of the deforming material.

Overall it is seen that Trial $8(A=987.8, B=1092, C=0.0139, n=0.41433$ and $m=1)$ predicts the cutting forces with good correlation to the experiments across the four cutting speeds.

\subsection{Cutting force sensitivity}

Fig. 2 shows the sensitivity of the cutting force response to the JC parameters at various cutting speeds. At $25 \mathrm{~m} / \mathrm{min}$ (Fig. 2a), the cutting force increases with parameter $A, B$ and $n$ while fluctuating for parameters $C$ and $m$. Parameter $A$ has the most influence on cutting force 
while $n$ has the least influence. At $40 \mathrm{~m} / \mathrm{min}$ (Fig. 2b), the cutting force increases with $A$ and fluctuates with the other parameters. Parameter $C$ has the most influence while parameter $n$ has the least influence. At $61 \mathrm{~m} / \mathrm{min}$ (Fig. 2c), the cutting force increases with $C$ and fluctuates with the other parameters with parameter $A$ showing the most influence and $n$ the least. At $93 \mathrm{~m} / \mathrm{min}$ (Fig. 2d), the cutting force increases with $C$ and $m$ and fluctuates with the other parameters with $A$ showing the most impact and $n$ the least. The overall analysis indicates that the yield strength $(A)$ has the most influential effect and the strain hardening exponent $(n)$ the least on the cutting force response. This explains the good cutting force predictions by Trial 8 and model M2 both having a common $A$ parameter (987.8) which was optimised through the CPSO process.
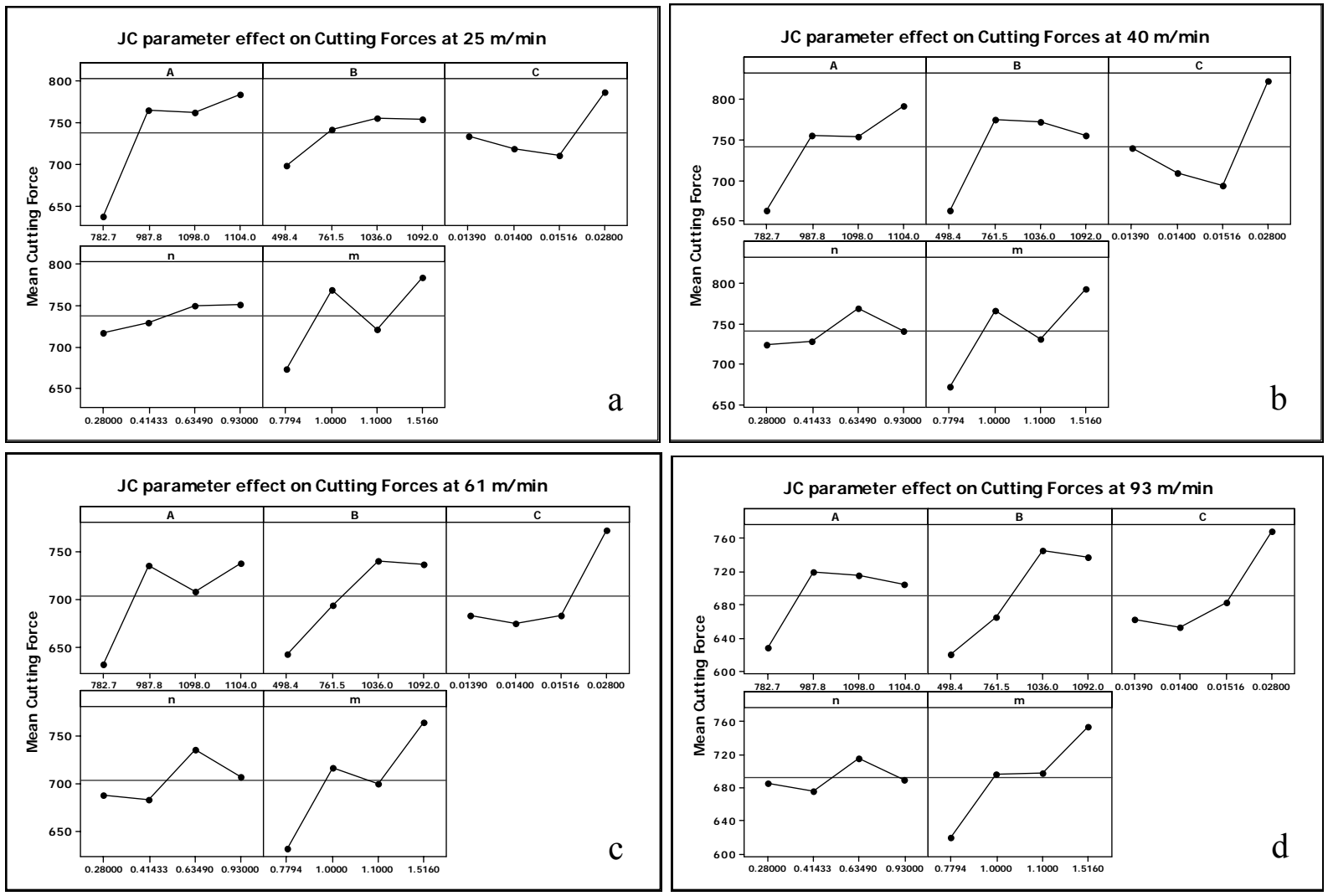

Figure 2: Sensitivity of cutting force to JC parameters.

\subsection{Feed force predictions}

Table VI shows the feed force predictions with the four JC models. The models under predicted the feed forces across various cutting speeds. The feed force is generally lower than the cutting force and a similar trend is found in the simulated results. Model M2 with parameters from the CPSO method predicts the feed force better than other models for 25, 40 and $61 \mathrm{~m} / \mathrm{min}$ and model M4 predicts better than other models at $93 \mathrm{~m} / \mathrm{min}$. The feed force is generally influenced by frictional condition between the chip and tool.

Table VII shows the feed force predictions by the JC parameter combinations from the Taguchi design optimisation methodology. The Taguchi design matrix showed a marked improvement in the feed force predictions compared to the conventional JC models. At 25 $\mathrm{m} / \mathrm{min}$, Trial 9 predicted with an error of $19.32 \%$, better than M2 by $18 \%$. At $40 \mathrm{~m} / \mathrm{min}$, Trial 6 predicted at $2.99 \%$ error, better than M2 by $25 \%$. At $61 \mathrm{~m} / \mathrm{min}$, Trial 6 predicted at $18.69 \%$ error better than M2 by $16 \%$. At $93 \mathrm{~m} / \mathrm{min}$, Trial 5 predicted at $42.67 \%$ better than M4 by $2 \%$. 
Table VI: Feed force predictions by the JC models.

\begin{tabular}{|c|c|c|c|c|}
\hline \multirow{2}{*}{$\begin{array}{c}\text { JC } \\
\text { models }\end{array}$} & \multicolumn{4}{|c|}{ Feed force $(\mathrm{N})$} \\
\cline { 2 - 5 } & $25 \mathrm{~m} / \mathrm{min}$ & $40 \mathrm{~m} / \mathrm{min}$ & $61 \mathrm{~m} / \mathrm{min}$ & $93 \mathrm{~m} / \mathrm{min}$ \\
\hline M1 & $346(-44.28)$ & $295(-36.96)$ & $277(-41.80)$ & $275(-48.98)$ \\
\hline M2 & $386(-37.84)$ & $336(-28.20)$ & $311(-34.66)$ & $294(-45.45)$ \\
\hline M3 & $334(-46.21)$ & $257(-45.08)$ & $222(-53.36)$ & $235(-56.40)$ \\
\hline M4 & $372(-40.09)$ & $302(-35.47)$ & $289(-39.28)$ & $297(-44.89)$ \\
\hline EXP & 621 & 468 & 476 & 539 \\
\hline
\end{tabular}

Table VII: Feed force predictions by the design matrix.

\begin{tabular}{|c|c|c|c|c|}
\hline \multirow{2}{*}{ Trials } & \multicolumn{4}{|c|}{ Feed force $(\mathrm{N})$} \\
\cline { 2 - 5 } & $25 \mathrm{~m} / \mathrm{min}$ & $40 \mathrm{~m} / \mathrm{min}$ & $61 \mathrm{~m} / \mathrm{min}$ & $93 \mathrm{~m} / \mathrm{min}$ \\
\hline 1 & $346(-44.28)$ & $295(-36.96)$ & $277(-41.80)$ & $275(-48.98)$ \\
\hline 2 & $334(-46.21)$ & $316(-32.47)$ & $293(-38.44)$ & $214(-60.29)$ \\
\hline 3 & $195(-68.59)$ & $291(-37.82)$ & $309(-35.08)$ & $196(-63.63)$ \\
\hline 4 & $309(-50.24)$ & $200(-57.26)$ & $218(-54.20)$ & $205(-61.96)$ \\
\hline 5 & $382(-38.48)$ & $353(-24.57)$ & $324(31.93)$ & $309(-42.67)$ \\
\hline 6 & $329(-47.02)$ & $454(-2.99)$ & $387(-18.69)$ & $262(-51.39)$ \\
\hline 7 & $269(-56.68)$ & $267(-42.94)$ & $266(-44.11)$ & $265(-50.83)$ \\
\hline 8 & $381(-38.64)$ & $356(-23.93)$ & $326(-31.51)$ & $288(-46.56)$ \\
\hline 9 & $501(-19.32)$ & $363(-22.43)$ & $292(-38.65)$ & $272(-49.53)$ \\
\hline 10 & $458(-26.24)$ & $438(-6.41)$ & $297(-37.60)$ & $231(-57.14)$ \\
\hline 11 & $366(-41.06)$ & $383(-18.16)$ & $268(-43.69)$ & $267(-50.46)$ \\
\hline 12 & $331(-46.69)$ & $304(-35.04)$ & $299(-37.18)$ & $294(-45.45)$ \\
\hline 13 & $343(-44.76)$ & $293(-37.39)$ & $234(-50.84)$ & $244(-54.73)$ \\
\hline 14 & $421(-32.20)$ & $319(-31.83)$ & $251(-47.26)$ & $255(-52.69)$ \\
\hline 15 & $387(-37.68)$ & $246(-47.43)$ & $260(-45.37)$ & $244(-54.73)$ \\
\hline 16 & $279(-55.07)$ & $284(-39.31)$ & $395(-17.01)$ & $309(-42.67)$ \\
\hline
\end{tabular}

Overall there was a 2-25\% improvement across the four cutting speeds which can be attributed to the better characterisation of the flow curve in modelling the deformation characteristics of titanium alloys. The inadequacy in conventional JC models in feed force predictions can be over come through the method suggested in this work though the JC law seems inadequate in modelling this machining characteristic. Trial 6 correlates the experiments better than trials 5 and 9 in the overall predictions across cutting speeds. Hence Trial 6 can be suggested as an optimised set of JC parameters for feed force predictions with titanium alloy machining.

\subsection{Feed force sensitivity}

Fig. 3 shows the sensitivity of the feed force response to the JC parameters for various cutting speeds. At a cutting speed of $25 \mathrm{~m} / \mathrm{min}$ (Fig. 3a), the feed force increases with parameter $A$ and fluctuates with the other parameters with parameter $m$ showing the most impact and parameter $C$ the least. At $40 \mathrm{~m} / \mathrm{min}$ (Fig. 3b), the feed force decreases with $m$ and fluctuates with the other parameters with parameter $B$ showing the highest influence and $m$ the least. At $61 \mathrm{~m} / \mathrm{min}$ (Fig. 3c), the feed force fluctuates with all the parameters with $A$ and $n$ showing the most influence and $B$ the least. At $93 \mathrm{~m} / \mathrm{min}$ (Fig. 3d), the feed force decreases with $m$ and fluctuates with other parameters with $A$ showing the highest influence and $m$ the least on the feed force response. The feed force is impacted most by parameter $A$ and least by parameter $m$ across most cutting speeds. The initial yield strength of the work material $(A)$ forms the most 
important part of the flow stress computation for accurate feed force predictions while the thermal softening coefficient $(m)$ has the least impact.
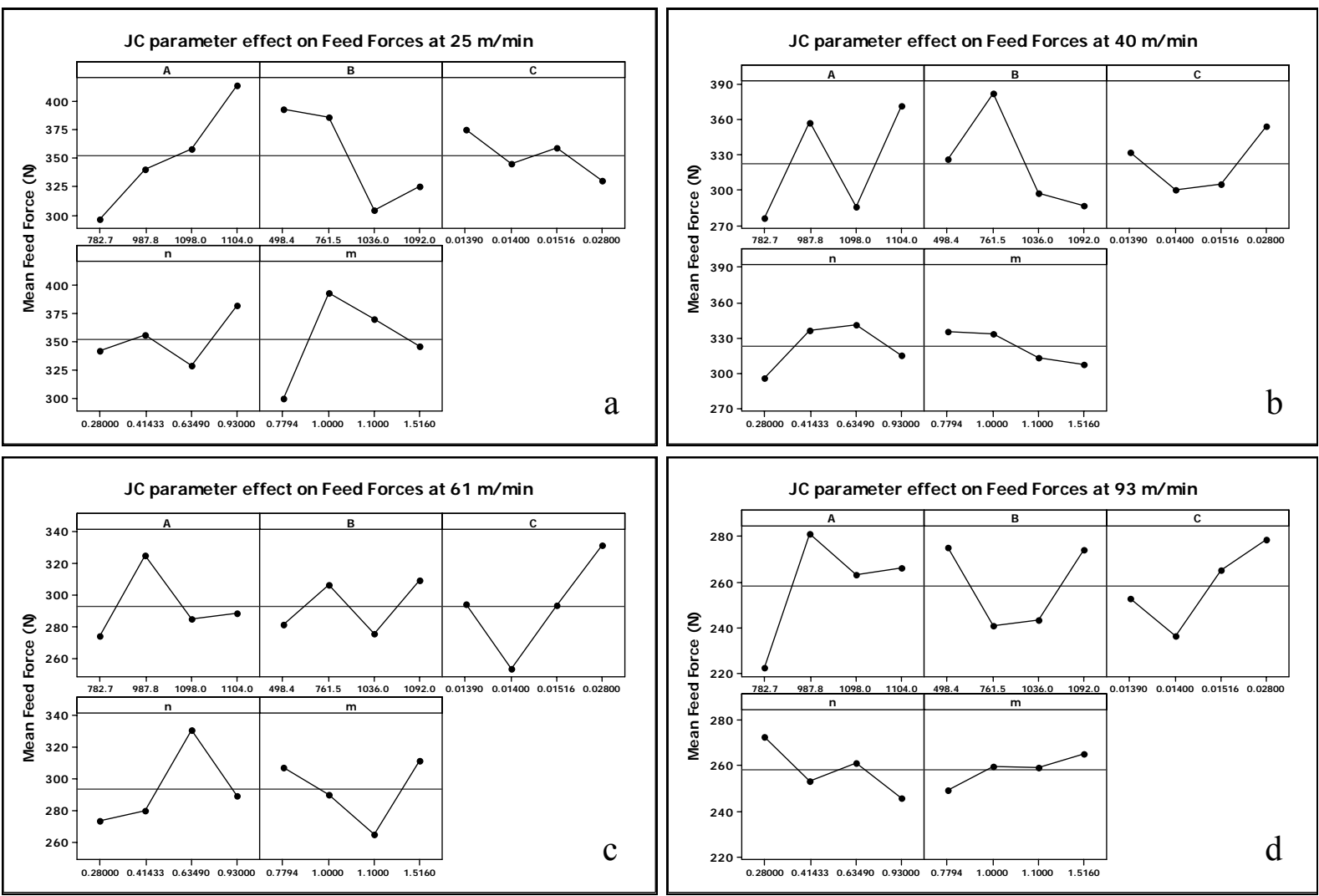

Figure 3: Sensitivity of feed force to JC parameters.

\subsection{Chip thickness ratio predictions}

Table VIII shows the CTR predictions for the JC models. The CTR is the true measure of plastic deformation in metal cutting and is used to estimate work done and power requirements in machining [24]. Model M2 predicted the CTR within $20 \%$ at $25 \mathrm{~m} / \mathrm{min}$, M1 predictions were equal to the experiments at $40 \mathrm{~m} / \mathrm{min}, \mathrm{M} 4$ predictions were within $19 \%$ at $61 \mathrm{~m} / \mathrm{min}$ and M1 and M2 predictions were within $8 \%$ at $93 \mathrm{~m} / \mathrm{min}$. Overall the models predicted in a range of $0-20 \%$ showing good predictions at a higher speed of $93 \mathrm{~m} / \mathrm{min}$.

Table VIII: CTR predictions by the JC models.

\begin{tabular}{|c|c|c|c|c|}
\hline \multirow{2}{*}{$\begin{array}{c}\text { JC } \\
\text { models }\end{array}$} & \multicolumn{4}{|c|}{ CTR } \\
\cline { 2 - 5 } & $25 \mathrm{~m} / \mathrm{min}$ & $40 \mathrm{~m} / \mathrm{min}$ & $61 \mathrm{~m} / \mathrm{min}$ & $93 \mathrm{~m} / \mathrm{min}$ \\
\hline M1 & $0.64(+52.38)$ & $0.50(0)$ & $0.64(+33.33)$ & $0.71(+7.57)$ \\
\hline M2 & $0.50(+19.04)$ & $0.52(+4)$ & $0.58(+20.83)$ & $0.61(-7.57)$ \\
\hline M3 & $0.68(+61.90)$ & $0.71(+42)$ & $0.73(+52.08)$ & $0.72(+9.09)$ \\
\hline M4 & $0.59(+40.47)$ & $0.61(+22)$ & $0.57(+18.75)$ & $0.60(-9.09)$ \\
\hline EXP & 0.42 & 0.50 & 0.48 & 0.66 \\
\hline
\end{tabular}

Table IX shows the CTR predictions with the design optimisation trials. At $25 \mathrm{~m} / \mathrm{min}$, Trial 5 predicts at an error of $7.14 \%$ better than M2 by $12 \%$. At $40 \mathrm{~m} / \mathrm{min}$, Trial 1 predicts with $0 \%$ error equal to M1. At $61 \mathrm{~m} / \mathrm{min}$, Trial 6 predicts with $0 \%$ error better than M4 by $18.75 \%$. At $93 \mathrm{~m} / \mathrm{min}$, Trial 14 predicts the CTR at $0 \%$ better than M1 and M2 by $7.57 \%$. 
The design trials were able to improve the CTR predictions across all cutting speeds. Trial 6 in particular predicts the CTR with good correlation to the experiments considering all cutting speeds and is suggested as an optimised JC parameter set for CTR predictions.

Table IX: CTR predictions by the design matrix.

\begin{tabular}{|c|c|c|c|c|}
\hline \multirow{2}{*}{ Trials } & \multicolumn{4}{|c|}{ CTR } \\
\cline { 2 - 5 } & $25 \mathrm{~m} / \mathrm{min}$ & $40 \mathrm{~m} / \mathrm{min}$ & $61 \mathrm{~m} / \mathrm{min}$ & $93 \mathrm{~m} / \mathrm{min}$ \\
\hline 1 & $0.64(+52.38)$ & $0.50(0)$ & $0.64(+33.33)$ & $0.71(+7.57)$ \\
\hline 2 & $0.54(+28.57)$ & $0.46(-8)$ & $0.53(+10.41)$ & $0.57(-13.63)$ \\
\hline 3 & $0.50(+19.04)$ & $0.53(+6)$ & $0.51(+6.25)$ & $0.49(-25.75)$ \\
\hline 4 & $0.40(-4.76)$ & $0.44(-12)$ & $0.46(-4.16)$ & $0.39(-40.90)$ \\
\hline 5 & $0.45(+7.14)$ & $0.54(+8)$ & $0.51(+6.25)$ & $0.49(-25.75)$ \\
\hline 6 & $0.49(+16.67)$ & $0.51(+2)$ & $0.48(0)$ & $0.54(-18.18)$ \\
\hline 7 & $0.59(+40.47)$ & $0.60(+20)$ & $0.58(+20.83)$ & $0.60(-9.09)$ \\
\hline 8 & $0.54(+28.57)$ & $0.58(+16)$ & $0.64(+33.33)$ & $0.77(+16.66)$ \\
\hline 9 & $0.47(+11.90)$ & $0.51(+2)$ & $0.53(+10.41)$ & $0.58(-12.12)$ \\
\hline 10 & $0.48(+14.28)$ & $0.51(+2)$ & $0.59(+22.91)$ & $0.52(-21.21)$ \\
\hline 11 & $0.58(+38.09)$ & $0.57(+14)$ & $0.60(+25)$ & $0.58(-12.12)$ \\
\hline 12 & $0.67(+59.52)$ & $0.73(+46)$ & $0.80(+66.66)$ & $0.76(+15.15)$ \\
\hline 13 & $0.63(+50)$ & $0.63(+26)$ & $0.64(+33.33)$ & $0.72(+9.09)$ \\
\hline 14 & $0.58(+38.09)$ & $0.59(+18)$ & $0.65(+35.41)$ & $0.66(0)$ \\
\hline 15 & $0.56(+33.33)$ & $0.41(-18)$ & $0.45(-6.25)$ & $0.63(-4.54)$ \\
\hline 16 & $0.45(+7.14)$ & $0.55(+10)$ & $0.47(-2.08)$ & $0.70(+6.06)$ \\
\hline
\end{tabular}

\subsection{Chip thickness ratio sensitivity}
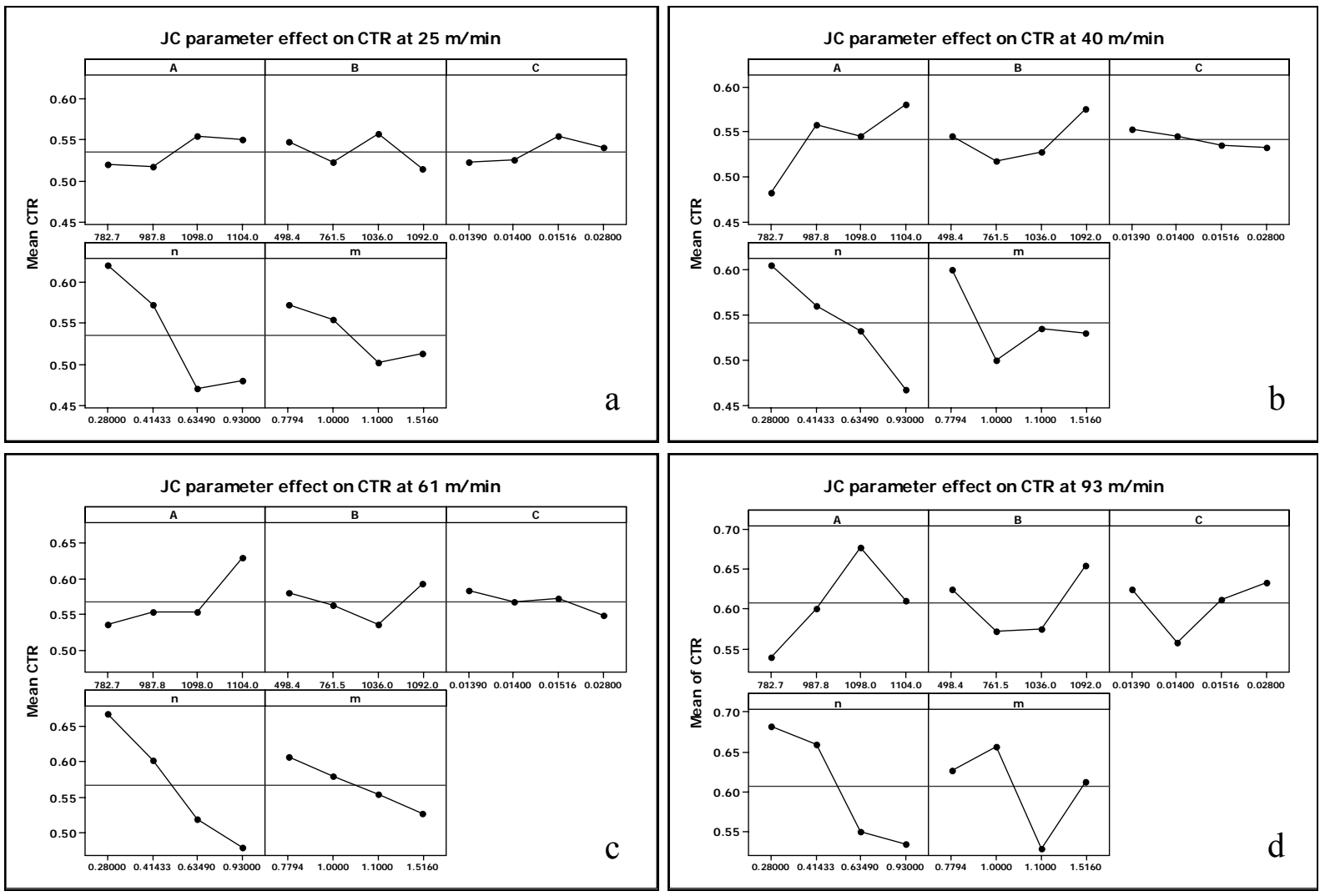

Figure 4: Sensitivity of CTR to JC parameters. 
Fig. 4 shows the effect of JC parameters on the CTR response for various cutting speeds. At $25 \mathrm{~m} / \mathrm{min}$ (Fig. 4a), the CTR increases with $A$, and fluctuates with the other parameters with parameter $n$ having the most effect and $C$ the least. At $40 \mathrm{~m} / \mathrm{min}$ (Fig. $4 \mathrm{~b}$ ), the CTR increases with $A$, decreases with $C$ and $n$ and fluctuates with the others. The parameter $\mathrm{m}$ has the most influence and $C$ the least. At $61 \mathrm{~m} / \mathrm{min}$ (Fig. 4c), the CTR increases with $A$, decreases with $C, n$ and $m$ and fluctuates with $B$ with parameter $A$ having the most influence and $C$ the least. At $93 \mathrm{~m} / \mathrm{min}$ (Fig. 4d), the CTR decreases with $n$ and fluctuates with other parameters with $m$ having the most impact and $C$ the least. Overall parameter $A$ influences the CTR response the most while $C$ has the least influence suggesting that the initial yield strength is the most influential parameter in the chip formation process.

\subsection{FE analysis of the optimised JC parameters}

Fig. 5 shows the FE plots for effective stress, strain, strain rate and temperature for the optimised JC parameters (Trial 8) at $93 \mathrm{~m} / \mathrm{min}$. The effective Von Mises stress (Fig. 5a) is highest at the shear plane and decreases along the chip - tool interface and least below the uncut surface and the free end of chip. The effective plastic strain is highest at the tool - chip interface and decreases at the shear plane and free end of the chip (Fig. 5b). The effective plastic strain rate is higher at the shear plane and less above and below the shear plane (Fig. $5 \mathrm{c})$.
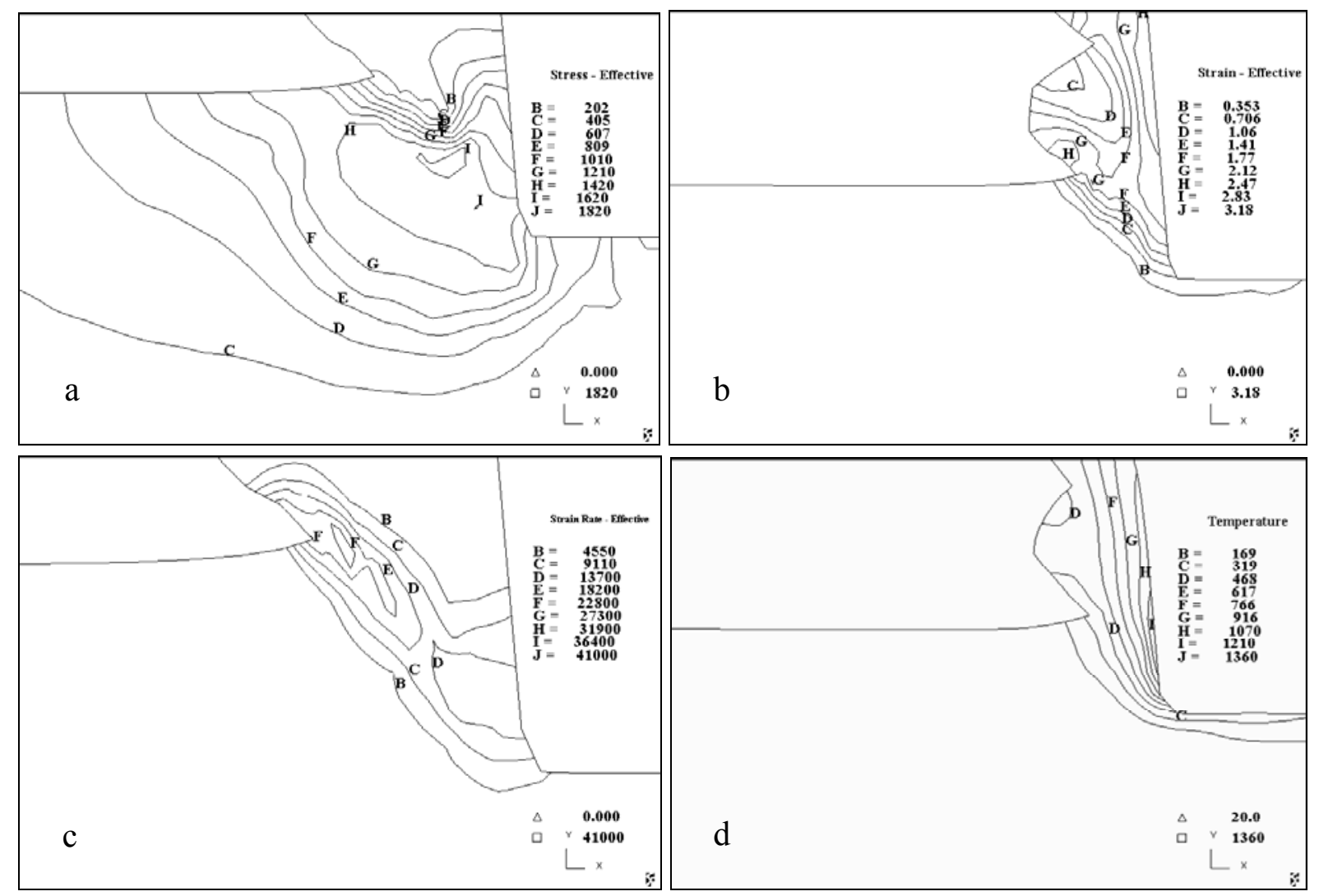

Figure 5: FE plots with the optimised JC parameter set: a) stress distribution,

b) strain distribution, c) strain rate distribution, d) temperature distribution.

The temperature is highest at the chip - tool interface due to higher frictional heat and decreases near the shear plane and other uncut areas. The higher temperatures at the chip tool interface increase the strain due to higher deformation and reduce the stress due to the increased plasticity of the work material. The low thermal conductivity of titanium alloys 
result in poor heat transfer through conduction and convection causing accelerated tool wear at the contact regions. (Fig. 5d). The effective stress, strain and strain rate plots conform to expectations while the temperature values are likely to be less than actual since the duration of cutting simulation is not sufficient to elicit a steady state response .The FE distributions indicate effectiveness of the optimised flow stress data and the robustness of the JC constitutive law in modelling the local deformation behaviour of Ti6Al4V.

\section{CONCLUSIONS}

The objective of the work was to optimise the material parameters of the JC model to suit machining simulation requirements given the varied nature of material parameter values available in literature. The comparative analysis with orthogonal cutting experiments with a tube of Ti6Al4V titanium alloy yielded a set of optimised parameters based on Taguchi concepts. The conclusions are as follows:

- There is an overall improvement in the cutting force predictions by $3-16 \%$, feed force predictions by $2-25 \%$ and CTR predictions by $0-19 \%$ by the Taguchi design matrix when compared to the predictions of the four JC model sets used in this study. The improvement can be attributed to the superior flow stress characterisation achieved by the proposed Taguchi - FE methodology. The optimised JC material parameter set for cutting force predictions is given by Trial 8: $A=987.8, B=1092, C=0.0139, n=0.41433, m=1$ and the optimised JC parameter set for feed force and CTR predictions is given by Trial 6: $A=987.8, B=761.5, C=0.028, n=0.93, m=0.7794$.

- The initial yield strength parameter $(A)$ is the only common parameter in the two optimised sets which is confirmed in the sensitivity analysis also. Future optimisation studies and search algorithms should concentrate on the yield strength coefficient. The results indicate that FE predictions are sensitive to flow stress model parameters and that for the same model different material parameter combinations produce varied FE output. The accurate descriptions of effective stress, strain, strain rate and temperature confirmed the robustness of the JC model in generating a flow stress curve matching the deformation behaviour of Ti6Al4V titanium alloy during the machining process.

The FE model used in this study is capable of simulating orthogonal cutting conditions and the Taguchi - FE methodology proposed is a simple and effective tool for optimising flow stress for machining simulations.

\section{REFERENCES}

[1] Shatla, M.; Christian, K.; Altan, T. (2001). Process modeling in machining. Part I: determination of flow stress data, International Journal of Machine Tools and Manufacture, Vol. 41, No. 10, 1511-1534, doi:10.1016/S0890-6955(01)00016-5

[2] Dirikolu, M. H.; Childs, T. H. C.; Maekawa, K. (2001). Finite element simulation of chip flow in metal machining, International Journal of Mechanical Sciences, Vol. 43, No. 11, 2699-2713, doi:10.1016/S0020-7403(01)00047-9

[3] Fang, N. (2005). A New Quantitative Sensitivity Analysis of the Flow Stress of 18 Engineering Materials in Machining, Journal of Engineering Materials and Technology, Vol. 127, No. 2, 192196, doi:10.1115/1.1857935

[4] Pujana, J.; Arrazola, P. J.; Saoubi, R. M.; Chandrasekaran, H. (2007). Analysis of the inverse identification of constitutive equations applied in orthogonal cutting process, Int. Journal of Machine Tools and Manufacture, Vol. 47, 2153-2161, doi:10.1016/j.ijmachtools.2007.04.012

[5] Chandrasekaran, H.; Saoubi, R. M.; Chazal, H. (2005). Modelling of material flow stress in chip formation process from orthogonal milling and split Hopkinson bar tests, Machining Science and Technology, Vol. 9, No. 1, 131-145, doi:10.1081/MST-200051380 
[6] Iqbal, S. A.; Mativenga, P. T.; Sheikh, M. A. (2007). Characterization of machining of AISI 1045 steel over a wide range of cutting speeds. Part 1: investigation of contact phenomena, Proceedings of the Institution of Mechanical Engineers, Part B: Journal of Engineering Manufacture, Vol. 221, No. 5, 909-916, doi:10.1243/09544054JEM796

[7] Umbrello, D. (2008). Finite element simulation of conventional and high speed machining of Ti6Al4V alloy, Journal of Materials Processing Technology, Vol. 196, No. 1-3, 79-87, doi:10.1016/j.jmatprotec.2007.05.007

[8] Calamaz, M.; Coupard, D.; Girot, F. (2008). A new material model for 2D numerical simulation of serrated chip formation when machining titanium alloy Ti-6Al-4V, Int. Journal of Machine Tools and Manufacture, Vol. 48, No. 3-4, 275-288, doi:10.1016/j.ijmachtools.2007.10.014

[9] Shao, F.; Liu, Z.; Wan, Y.; Shi, Z. (2010). Finite element simulation of machining of Ti-6Al-4V alloy with thermodynamical constitutive equation, International Journal of Advanced Manufacturing Technology, Vol. 49, No. 5-8, 431-439, doi:10.1007/s00170-009-2423-y

[10] Shi, B.; Attia, H.; Tounsi, N. (2010). Identification of Material Constitutive Laws for Machining - Part I: An Analytical Model Describing the Stress, Strain, Strain Rate, and Temperature Fields in the Primary Shear Zone in Orthogonal Metal Cutting, Journal of Manufacturing Science and Engineering, Vol. 132, No. 5, 1-11, doi:10.1115/1.4002454

[11] Sima, M.; Ozel, T. (2010). Modified material constitutive models for serrated chip formation simulations and experimental validation in machining of titanium alloy Ti-6Al-4V, Int. Journal of Machine Tools and Manufacture, Vol. 50, 943-960, doi:10.1016/j.ijmachtools.2010.08.004

[12] Dusunceli, N.; Colak, O. U.; Filiz, C. (2010). Determination of material parameters of a viscoplastic model by genetic algorithm, Materials and Design, Vol. 31, No. 3, 1250-1255, doi:10.1016/j.matdes.2009.09.023

[13] Ozel, T.; Karpat, Y. (2007). Identification of constitutive material model parameters for high strain rate metal cutting conditions using evolutionary computational algorithms, Materials and Manufacturing Processes, Vol. 22, No. 5, 659-667, doi:10.1080/10426910701323631

[14] Mousavi Anijdan, S. H.; Madaah-Hosseini, H. R.; Bahrami, A. (2007). Flow stress optimization for 304 stainless steel under cold and warm compression by artificial neural network and genetic algorithm, Materials and Design, Vol. 28, No. 2, 609-615, doi:10.1016/j.matdes.2005.07.018

[15] Lee, W. S.; Lin, C. F. (1998). High temperature deformation behaviour of Ti6A14V alloy evaluated by high strain rate compression tests, Journal of Materials Processing Technology, Vol. 75, No. 1-3, 127-136, doi:10.1016/S0924-0136(97)00302-6

[16] Khan, A. S.; Suh, Y. S.; Kazmi, R. (2004). Quasi-static and dynamic loading responses and constitutive modelling of titanium alloys, International Journal of Plasticity, Vol. 20, No. 12, 2233-2248, doi:10.1016/j.ijplas.2003.06.005

[17] Lesuer, D. R. (2000). Experimental investigations of material models for Ti-6Al-4V titanium and 2024-T3 aluminum. Final Report, DOT/FAA/AR-00/25, US Department of Transportation, Federal Aviation Administration

[18] Motorcu, A. R. (2010). The Optimization of Machining Parameters Using the Taguchi Method for Surface Roughness of AISI 8660 Hardened Alloy Steel, Strojniški vestnik - Journal of Mechanical Engineering, Vol. 56, No. 6, 391-401

[19] Ghose, J.; Sharma, V.; Kumar, N.; Krishnamurthy, A.; Kumar, S.; Botak, Z. (2011). Taguchifuzzy based mapping of EDM-machinability of aluminium foam, Technical Gazette, Vol. 18, No. 4, 595-600

[20] Gurbuz, H.; Kurt, A.; Ciftci, I.; Seker, U. (2011). The Influence of Chip Breaker Geometry on Tool Stresses in Turning, Strojniški vestnik - Journal of Mechanical Engineering, Vol. 57, No. 2, 91-99, doi:10.5545/sv-jme.2009.191

[21] Kovacevic, D.; Budak, I.; Antić, A.; Kosec, B. (2011). Special finite elements: Theoretical background and application, Technical Gazette, Vol. 18, No. 4, 649-655

[22] Johnson, G. J.; Cook, W. H. (1983). A constitutive model and data for metals subjected to large strains, high strain rates and high temperatures, Proceedings of the Seventh International Symposium on Ballistics, The Hague, 541-547

[23] Ross, P. J. (1996). Taguchi techniques for quality engineering, Tata McGraw Hill

[24] Astakhov, V. P.; Shvets, S. (2004). The assessment of plastic deformation in metal cutting, J. of Materials Processing Technology, Vol. 146, 193-202, doi:10.1016/j.jmatprotec.2003.10.015 